\title{
Risks of Exploitation of Tavush Reservoir
}

\author{
Vache Tokmajyan \\ Institute of water problems and hydro-engineering named after I.V. Yeghiazarov, Armenakyan 125, \\ Yerevan, Armenia
}

doi: https://doi.org/10.21467/abstracts.93.22

\begin{abstract}
Armenia is a mountainous country with complicated relief. The vast majority of its area is located on more than $1000 \mathrm{~m}$ above sea level. All the rivers of Armenia belong to the Caspian basin and flow into the Kur or its tributary the Araks. The only exceptions are the rivers flowing into Lake Sevan. The river water is characterized by an uneven distribution of flow with vividly expressed full spring water and a sharp reduction of water level during the deficit period. Only one third of the surface and groundwater in the territory of Armenia is used for agricultural, industrial, domestic and other purposes. In particular, a part of the flood is accumulated in reservoirs during spring months and most of it flows out of the borders of the republic. In this regard, during the spring floods, the problem of water accumulation becomes extremely urgent.

About eighty reservoirs built in Armenia satisfy the demand for irrigation of agricultural lands, provide energy and production facilities regulating the annual flows of rivers. The fact is that, as a rule, a large number of settlements, important communication routes and highways are located below the reservoirs, hence the latter become high risk structures. Therefore, ensuring the safety of the reservoirs and their nodes is of vital and strategic importance. In this regard the discovery of reservoir safety standards is of primary importance. After exploitation of ground hydraulic structures their monitoring is mandatory during several years during which data on filtration flow, sediment, firmness, overfall and stability of the dam and other hydraulic structures are collected. Based on the analysis of the collected data, conclusions are made on the technical state of the structures.

Our aim is to conduct observation studies of the technical state of the Tavush waterworks facility to determine the possibilities for further exploitation of separate nodes in the structure, to make suggestions for developing an engineering action plan that will create conditions for their long-term safe operation. For this purpose, observation studies of the technical condition of the dam and its separate nodes were conducted and preliminary analyses of descriptions of alluvial accumulations in the reservoir and the separate nodes located in the dam and preliminary assessments of the technical condition were carried out. Safety declarations should be submitted for those hydraulic structures that can cause emergency situations, for their design, construction, operation, exploitation, removal, restoration or abolition and for their temporary stop or operational abortion as well in case of their involvement in economic activity.

Such reservoirs are those having 300,000 cube meters storage and/or those reservoirs, tailing dumps and dams which have more than $10 \mathrm{~m}$ height and those hydro power stations and pumping stations having more than one MWt power electricity. Security declaration is the key official document containing information on compliance with HTS security standards. Tavush Reservoir should have a security declaration.

Tavush Reservoir was built in 1975 on the same river. It has an area of about 40 hectares, 5 million $\mathrm{m}^{3}$ total storage, 1,9 km length and $360 \mathrm{~m}$ maximum width. By regulating the flows of Tavush River, the reservoir provides irrigation water to 1200 hectares of agricultural lands for the villages of Verin Karmiraghbyur, Movsesagegh, Tavush and Nerkin Karmiraghbyur.
\end{abstract}

(C) 2020 Copyright held by the author(s). Published by AIJR Publisher in "Abstracts of The Second Eurasian RISK-2020 Conference and Symposium" April 12- 19, 2020, Tbilisi, Georgia. Jointly organized by AMIR Technical Services LLC, Georgian Technical University, Institute of Geography (Kazakhstan) and Russian Institute of Petroleum Geology and Geophysics.

AijR DOI: $10.21467 /$ abstracts. 93 
The Second Eurasian RISK-2020 Conference and Symposium

Tavush Reservoir is a facility of first-rate danger the safe operation of which periodic inspections should be carried out for and any risk factors that may cause accidents should be identified. Therefore, investigation of safety standards for structures of Tavush reservoir is of vital importance. An observational study revealed that the filtration flows through the clay body are unchanged which indicates a sufficient filtration stability of the clay body. Filtration flow measurement and laboratory tests are not carried out which is important for detecting or excluding the occurrence of ground wash of the dam.

Piezometers are installed in the body of the dam to obtain the appearance of a depressive curve in four cuttings of lower side of the dam the indications of which are not recorded. It is necessary to study the technical state of the piezometric network and, if necessary, to develop measures to restore it, to perform filter stability studies and to compare quantitative and qualitative indicators of filter flows with design values and risk assessment. The emergency spillway located on the left wing of the reservoir is an open trench type. Studies should be carried out in order to find out its technical condition. In order to detect the physicalmechanical properties of the soil of the dam, it is necessary to perform digging and laboratory testing of the obtained samples.

To determine the seismic zone of the reservoir site and possible seismic loads, a microcirculation of the area should be performed to calculate the strength and stability of the dam body by combining the results and the drill test data. Technical analysis of the drainage system of the reservoir (removal pipeline, service tunnel, hydro-mechanical equipment), risk assessment and development of recommendations should also be carried out. It is also recommended to carry out research and provide justifications for accumulating additional storages above the normal basin horizon.

For this purpose, it is recommended to use the automatic valves which we have developed. When the water level rises to its limit in the reservoir, the valve shield moves to the opening as the size of openness depends on the size of the outlet entering the reservoir. If the flood outflow continues to increase, the opening of the valve also increases and vice versa. According to time duration the valve is repeatedly opened and closed during all the time of flood flow depending on the change of the outflow of the reservoir and after the last closure an additional storage of water is accumulated in the reservoir the theoretical maximum of which is equal to the composition of the water table surface of the reservoir and water level limit. The velocity of the opening and closing process of the valve is regulated by a hydraulic damper which enables to reduce the fluctuation in water level and makes the amount of accumulated storage in the reservoir approach its limited dimension. In other words, during the opening and closing operations of the valve there is already an additional accumulated storage in the reservoir and only after the last closure it reaches the limit.

It is necessary to assess the current technical condition of irrigation pipeline of the reservoir through instrumental surveys and to develop engineering measures to ensure its safe and long-term operation. It is also necessary to conduct surveys to assess the technical condition of the irrigation pipeline and the tunnel crossing the bed of the reservoir. It is possible to determine the storage of alluvial accumulations in the reservoir through measurements and to determine its distribution. This will allow to predict the spatial pattern of accumulated alluvial which is important for the development of operating regulations for the structures, especially for the determination of the operational period of the hydropower plant.

It is particularly important to investigate the peculiarities of the phenomenon of silt accumulation observed in the reinforced concrete tunnel-tower sidewall node (there is a $7-8 \mathrm{~cm}$ thick ceiling silt on the boundary of ceiling-tower of the tunnel) and to develop measures to eliminate and/or stabilize the event. 